\title{
Preliminary comparison of three processes of AIN oxidation: dry, wet and mixed ones
}

\author{
R. KorbutowiCZ* , A. ZAKRZEWSKI \\ Faculty of Microsystem Electronics and Photonics, Wroclaw University of Technology, \\ Janiszewskiego 11-17, 50-370 Wroclaw, Poland
}

\begin{abstract}
Three methods of AIN layers oxidation: dry, wet and mixed (wet with oxygen) were compared. Some physical parameters of oxidized thin films of aluminum nitride (AIN) layers grown on silicon $\operatorname{Si}\left(\begin{array}{lll}1 & 1 & 1\end{array}\right)$ were investigated by means Energy-Dispersive X-ray Spectroscopy (EDS) and Spectroscopic Ellipsometry (SE). Three series of the thermal oxidations processes were carried out at $1012{ }^{\circ} \mathrm{C}$ in pure nitrogen as carrying gas and various gas ambients: (a) dry oxidation with oxygen, (b) wet oxidation with water steam and (c) mixed atmosphere with various process times. All the research methods have shown that along with the rising of the oxidation time, AlN layer across the aluminum oxide nitride transforms to aluminum oxide. The mixed oxidation was a faster method than the dry or wet ones.
\end{abstract}

Keywords: thermal oxidation; $\mathrm{AlN} ; \mathrm{Al}_{2} \mathrm{O}_{3} ; \mathrm{AlON} ; \mathrm{EDS} ; \mathrm{SE}$

(C) Wroclaw University of Technology.

\section{Introduction}

III-N semiconductor compounds have been widely known for many years as a source for fabrication of many types of microelectronic and photonic devices, such as electroluminescent, laser, microwave diodes; UV photodetectors, high power transistors [1]. III-N oxides find application in contemporary microelectronics, MOS (Metal-OxideSemiconductors) [2-4], and MIS (Metal-InsulatorSemiconductor) $[5,6]$ devices for e.g. gas sensing. There are potentially many ways and means to make group III oxides [7]. The most popular are vacuum sputtering, plasma oxidation or similar techniques, however, they may damage semiconductor structures of these devices. One of the simplest methods (in terms of apparatus) is thermal oxidation of III-N which is very promising for this purpose. Determination of material parameters e.g. elements contents or refractive indices in oxidized layers is a serious problem. There is a lack of materials parameters for aluminum oxynitrides $\mathrm{Al}_{\mathrm{x}} \mathrm{O}_{\mathrm{y}} \mathrm{N}_{\mathrm{z}}$. Thermal oxidation of double semiconductor compounds, such as GaN or AlN is not easy

*E-mail: ryszard.korbutowicz@pwr.edu.pl to perform: the elements - aluminum and nitrogen - can form several temporary and/or permanent stable chemical compounds with oxygen. These components differently react with oxygen and water. AIIINs are thermodynamically unstable as $\mathrm{N}$ has a high partial pressure. Generally, in III-nitrides, oxygen substitutes nitrogen because of the high chemical affinity of aluminum, gallium or indium to oxygen but the exchange process has many steps.

\section{Experimental}

In all experiments epitaxial AlN layers with a thickness of about $200 \mathrm{~nm}$, deposited on 2" Si(l 11 1) in Metal Organic Vapor Phase Epitaxy (MOVPE) were used. After epitaxy, the wafers were cut into $10 \mathrm{~mm} \times 10 \mathrm{~mm}$ pieces. To remove the native oxides from the surfaces, all samples, before oxidizing, were cleaned in three steps: (a) degreasing, (b) native oxides etching and (c) purging. The samples were cleaned in TRI followed by acetone and methanol in an ultrasonic bath for 5 minutes, and then rinsed in DI water. After degreasing, the samples were rinsed in buffered $\left(\mathrm{HF}_{2} \mathrm{NH}_{4}\right) \mathrm{HF}$ for 10 minutes and then purged in DI water. Finally, the wafers were dried in compressed nitrogen $\mathrm{N}_{2}$. 
After cleaning, the samples were placed in a quartz boat and put into the quartz reactor to thermal oxidation. A system of various time of oxidation with fixed gas flows $\left(\mathrm{N}_{2}, \mathrm{O}_{2}, \mathrm{H}_{2} \mathrm{O}\right.$ steam) was used.

To determine the parameters of obtained structures they were measured and surveyed by means of optical microscope, Energy-Dispersive X-ray Spectroscopy EDS and Spectroscopic Ellipsometry SE.

\subsection{Oxidation}

The samples oxidation was performed in a three-zone resistance furnace with a gas manifold (nitrogen and oxygen) and water bath. The thermal oxidation system - open chamber reactor (Fig. 1) - was described in the literature [7, 8]. All pipes and quartz tubular reactor were purged by nitrogen (with purity better than $6 \mathrm{~N}$ ). In total, the gas streams in the reactor were almost the same: ca $2 \mathrm{~s} \mathrm{~m}$. In all processes, the oxidation temperature was fixed at $1012{ }^{\circ} \mathrm{C}$.

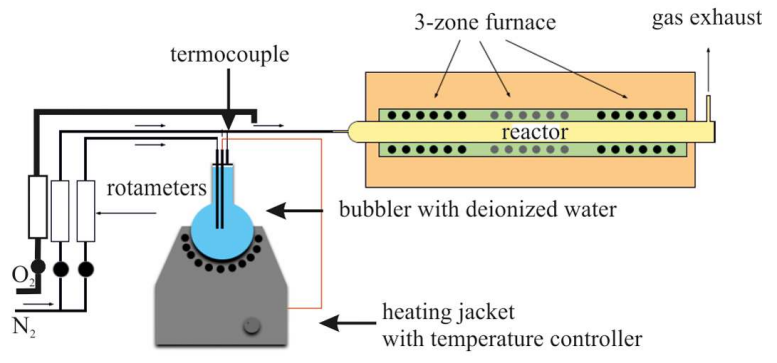

Fig. 1. Schematic diagram of the used thermal oxidation system.

\section{Dry oxidation}

The dry thermal oxidation processes of AlN were carried out in an atmosphere of a mixture of nitrogen and oxygen. The gas flow rates were kept at $1.2 \mathrm{slm}$ for nitrogen and $0.75 \mathrm{slm}$ for oxygen. Time of the oxidation was 10, 30, 50 and 100 minutes.

\section{Wet oxidation}

In the wet oxidation the main nitrogen flux was fixed at $1.1 \mathrm{slm}$. The second gas source was water steam from a water bubbler with hot deionized water $\left(96^{\circ} \mathrm{C}\right)$. Nitrogen passing through the DI water carried the steam into the reactor with a flow rate of about $0.8 \mathrm{slm}$. The time of the oxidation was 10 , 30,50 and 100 minutes.

\section{Mixed oxidation}

$\mathrm{N}_{2}$ was bubbled in the hot deionized water in the saturator $\left(96{ }^{\circ} \mathrm{C}\right)$ and the steam were transported into the reactor. The second source of oxygen was $6 \mathrm{~N} \mathrm{O}_{2}$. The oxidation processes were carried out in a mixed regime that means mixed atmosphere: main nitrogen $(0.9 \mathrm{~L} / \mathrm{min})+$ oxygen $(0.3 \mathrm{~L} / \mathrm{min})+$ nitrogen $(0.8 \mathrm{~L} / \mathrm{min})$ with a water steam from the saturator. The oxidation time was changed from 10 to 50 minutes with a step of 10 minutes.

\subsection{Spectroscopic ellipsometry measure- ments}

The optical parameters and thickness of fabricated layers of the heterostructures were measured with a V-VASE ellipsometer made by J.A. Woollam Company. The information about the amplitude ratio $\Psi$ and phase difference $\Delta$ as a function of wavelength was obtained. The fabricated heterostructures were measured in the wavelength range of 300 to $1700 \mathrm{~nm}$ with a $10 \mathrm{~nm}$ step at three different incident angles 65, 70 and 75 degree, automatically. The mathematical model describing the heterostructure was fitted based on parameters $\Psi$ and $\Delta$. The optical parameters of AlN layers were approximated by the Cauchy model in order to obtain the best fit of the model. The EMA Bruggeman model [9] was used in case of composite films AlN Cauchy + \% Void and $\mathrm{Al}_{2} \mathrm{O}_{3}+\%$ Void. In such model, based on dielectric functions of both materials, a mathematical model is created by the fit volume fractions of components. The quality of the mathematical model fit to the data obtained by ellipsometric measurements is defined by the mean square error (MSE). The scheme of fitting the mathematical model to the results of ellipsometric measurements of the fabricated heterostructures is presented in Fig. 2.

The proposed mathematical model of the sample before oxidation (time $\mathrm{t}_{0}$ ) comprises an $\mathrm{Si}$ substrate and AlN layer represented by an AlN layer approximated by a Cauchy model and a top thin 


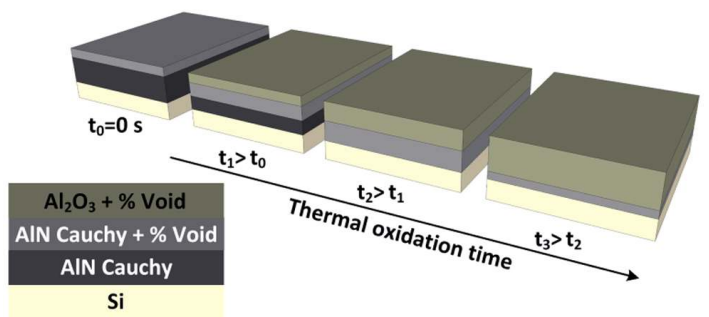

Fig. 2. Schematic view of the mathematical model system.

composite film of AlN Cauchy and various void content. The void content is a convenient way to adjust the refractive index of an analyzed layer. The time intervals $t_{1}, t_{2}, t_{3}$ correspond to the increasing of oxidation time. The thickness of AlN Cauchy layer decreases and the thicknesses of AlN Cauchy $+\%$ Void and $\mathrm{Al}_{2} \mathrm{O}_{3}+\%$ void layers increase at the first stage of oxidation (time $t_{1}$ ). At the time $t_{2}$, the AlN Cauchy layer is fully oxidized and the thicknesses of intermediate and top layers continue to grow. In the last stage of the oxidation process (time $\mathrm{t}_{3}$ ), the thickness of $\mathrm{Al}_{2} \mathrm{O}_{3}+\%$ Void layer increases at the expense of AlN Cauchy $+\%$ Void thickness. More detailed analysis is presented in Results and discussion section.
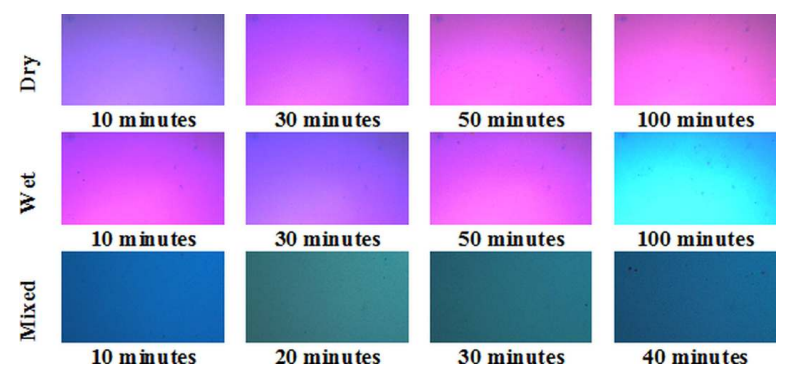

Fig. 3. Morphology of the oxidized AlN/Si surfaces.

\subsection{Energy-Dispersive X-ray Spectro- scopy measurements}

The surface of the oxidized samples was observed by SEM Hitachi SU6600. The apparatus has built-in EDS analyzer that was utilized to obtain quantitative results for the nitrogen and oxygen content in the structures. The signals came from $\mathrm{K}$-orbit of the atoms. The device acquired the data about the contents of aluminum, nitrogen and oxygen in the samples. EDS observations of the oxidized AIN/Si samples were carried out with electron beam energy of $5 \mathrm{kV}$.

\section{Results and discussion}

\subsection{Optical microscope survey}

The surfaces of the manufactured structures were observed by means of optical microscope (Fig. 3). It is easy to notice that the colors of the surfaces are changing with the oxidation time, the oxidized layers are growing thicker.

\subsection{SE measurements}

The ellipsometric measurements of the AlN layers were carried out at the first step. A mathematical model, consisting of a Si substrate, AlN layer approximated by Cauchy model, a top thin composite film of AlN Cauchy and various void contents, was created (time $t_{0}$ in Fig. 2). The composite film was created by EMA (Effective Medium Approximation layer) which is an interpolation between the constituent optical constants. Bruggeman, Maxwell-Garnett or linear type theory may be used to describe the EMA. Taking into consideration the analyzed heterostructures, the Bruggeman EMA seems to be the most accurate [10]. The results of fitting mathematical model to the results obtained by ellipsometry are presented in Fig. 4.

The heterostructure analyzed at the first step was thermally oxidized at different times and in three different processes: dry, wet and mixed. Consequently, $\mathrm{Al}_{2} \mathrm{O}_{3}$ layers were fabricated. The ellipsometry studies were carried out in order to obtain optical parameters and thicknesses of intermediate AlN Cauchy and top $\mathrm{Al}_{2} \mathrm{O}_{3}$ layers for each oxidation process and time. The new mathematical model includes the model created on the basis of earlier studies and top EMA of $\mathrm{Al}_{2} \mathrm{O}_{3}$ and various void contents (time intervals $t_{1}, t_{2}, t_{3}$ in Fig. 2). The ellipsometry database was the source 
Table 1. Results obtained from SE for the oxidized structures (dry type).

\begin{tabular}{|c|c|c|c|c|c|c|c|}
\hline \multirow{2}{*}{ Sample } & \multirow{2}{*}{$\begin{array}{c}\text { Thermal oxidation } \\
\text { time [min] }\end{array}$} & \multirow{2}{*}{$\begin{array}{c}\text { AlN Cauchy } \\
\text { Thickness [nm] }\end{array}$} & \multicolumn{2}{|c|}{ AlN Cauchy + Void } & \multicolumn{2}{|c|}{$\mathrm{Al}_{2} \mathrm{O}_{3}+$ Void } & \multirow{2}{*}{ - MSE } \\
\hline & & & Thickness [nm] & Void [\%] & Thickness [nm] & Void [\%] & \\
\hline test_aln & 0 & 181 & 44 & 51 & 0 & 100 & 18.34 \\
\hline As33 & 10 & 154 & 45 & 12 & 38 & 44 & 16.13 \\
\hline As34 & 30 & 140 & 47 & 10 & 44 & 43 & 19.02 \\
\hline As35 & 50 & 134 & 48 & 11 & 45 & 44 & 19.17 \\
\hline As36 & 100 & 105 & 68 & 8 & 51 & 38 & 23.91 \\
\hline
\end{tabular}

Table 2. Results obtained from SE for the oxidized structures (wet type).

\begin{tabular}{|c|c|c|c|c|c|c|c|}
\hline \multirow{2}{*}{ Sample } & \multirow{2}{*}{$\begin{array}{c}\text { Thermal oxidation } \\
\text { time [min] }\end{array}$} & \multirow{2}{*}{$\begin{array}{c}\text { AlN Cauchy } \\
\text { Thickness [nm] }\end{array}$} & \multicolumn{2}{|c|}{ AlN Cauchy + Void } & \multicolumn{2}{|c|}{$\mathrm{Al}_{2} \mathrm{O}_{3}+$ Void } & \multirow{2}{*}{ - MSE } \\
\hline & & & Thickness [nm] & Void [\%] & Thickness [nm] & Void [\%] & \\
\hline test_aln & 0 & 181 & 44 & 51 & 0 & 100 & 18.34 \\
\hline As 37 & 10 & 145 & 41 & 10 & 40 & 41 & 16.39 \\
\hline As39 & 30 & 116 & 62 & 11 & 49 & 27 & 21.32 \\
\hline As 38 & 50 & 78 & 87 & 9 & 58 & 19 & 23.93 \\
\hline As 40 & 100 & 40 & 114 & 12 & 82 & 10 & 21.24 \\
\hline
\end{tabular}
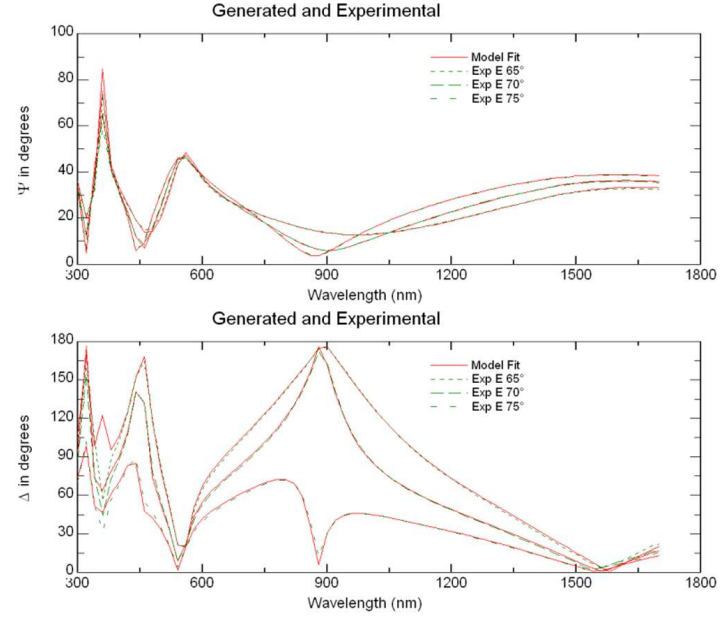

Fig. 4. Mathematical model fit to the results obtained by ellipsometry measurements: (a) amplitude ratio $\Psi$ and (b) phase difference $\Delta$ for sample $\mathrm{X}$ (not oxidized $\mathrm{AlN} / \mathrm{Si}$ ).

of optical parameters of $\mathrm{Al}_{2} \mathrm{O}_{3}$ used in the EMA model. The mathematical model fits to the results obtained by ellipsometry measurements of the sample As19 (10 minutes, mixed type of oxidation) are presented in Fig. 5.

The results obtained by the ellipsometry studies are presented in Table 1, Table 2 and Table 3.
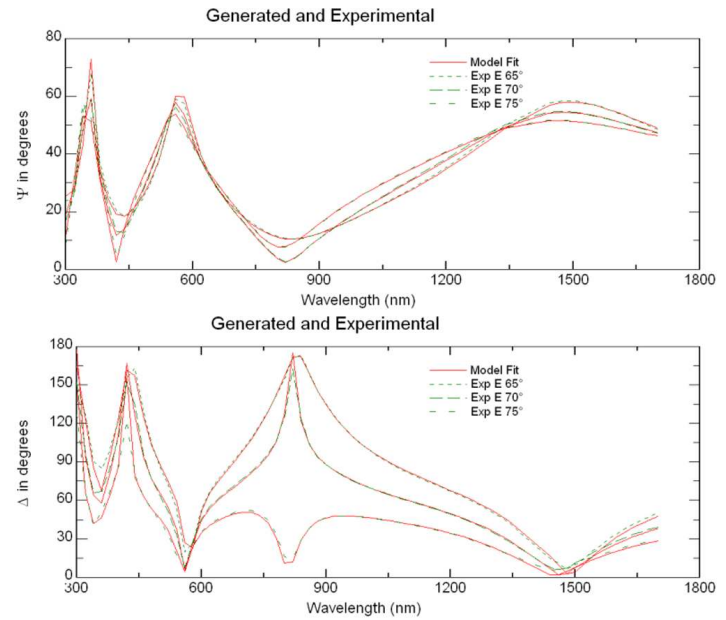

Fig. 5. Mathematical model fits to the results obtained by ellipsometry measurements: (a) amplitude ratio $\Psi$ and (b) phase difference $\Delta$ for sample As19.

The "X" and "test_aln" samples were the reference samples (without oxidation). The appearance of the structure presented in Fig. 2 is a result of consideration and analysis coming from computer modeling and fitting of measured ellipsometric data. We obtained the complex composite layered structures with changing thicknesses. The Tables, mentioned 
Table 3. Results obtained from SE for the oxidized structures (mixed type).

\begin{tabular}{|c|c|c|c|c|c|c|c|}
\hline \multirow{2}{*}{ Sample } & \multirow{2}{*}{$\begin{array}{c}\text { Thermal oxidation } \\
\text { time [min] }\end{array}$} & \multirow{2}{*}{$\begin{array}{c}\text { AlN Cauchy } \\
\text { Thickness [nm] } \\
\end{array}$} & \multicolumn{2}{|c|}{ AlN Cauchy + Void } & \multicolumn{2}{|c|}{$\mathrm{Al}_{2} \mathrm{O}_{3}+$ Void } & \multirow{2}{*}{ MSE } \\
\hline & & & Thickness [nm] & Void [\%] & Thickness [nm] & Void [\%] & \\
\hline $\mathrm{X}$ & 0 & 213 & 62 & 53.1 & 0 & 100 & 8.62 \\
\hline As19 & 10 & 140 & 72 & 13.2 & 59 & 29.2 & 7.349 \\
\hline As21 & 20 & 98 & 93 & 11.2 & 76 & 19.7 & 13.9 \\
\hline As2 & 30 & 48 & 107 & 8.7 & 124 & 17.6 & 12.69 \\
\hline As22 & 40 & 0 & 131 & 7.9 & 165 & 15.8 & 17.1 \\
\hline As20 & 50 & 0 & 105 & 7.2 & 187 & 15.3 & 12.23 \\
\hline
\end{tabular}
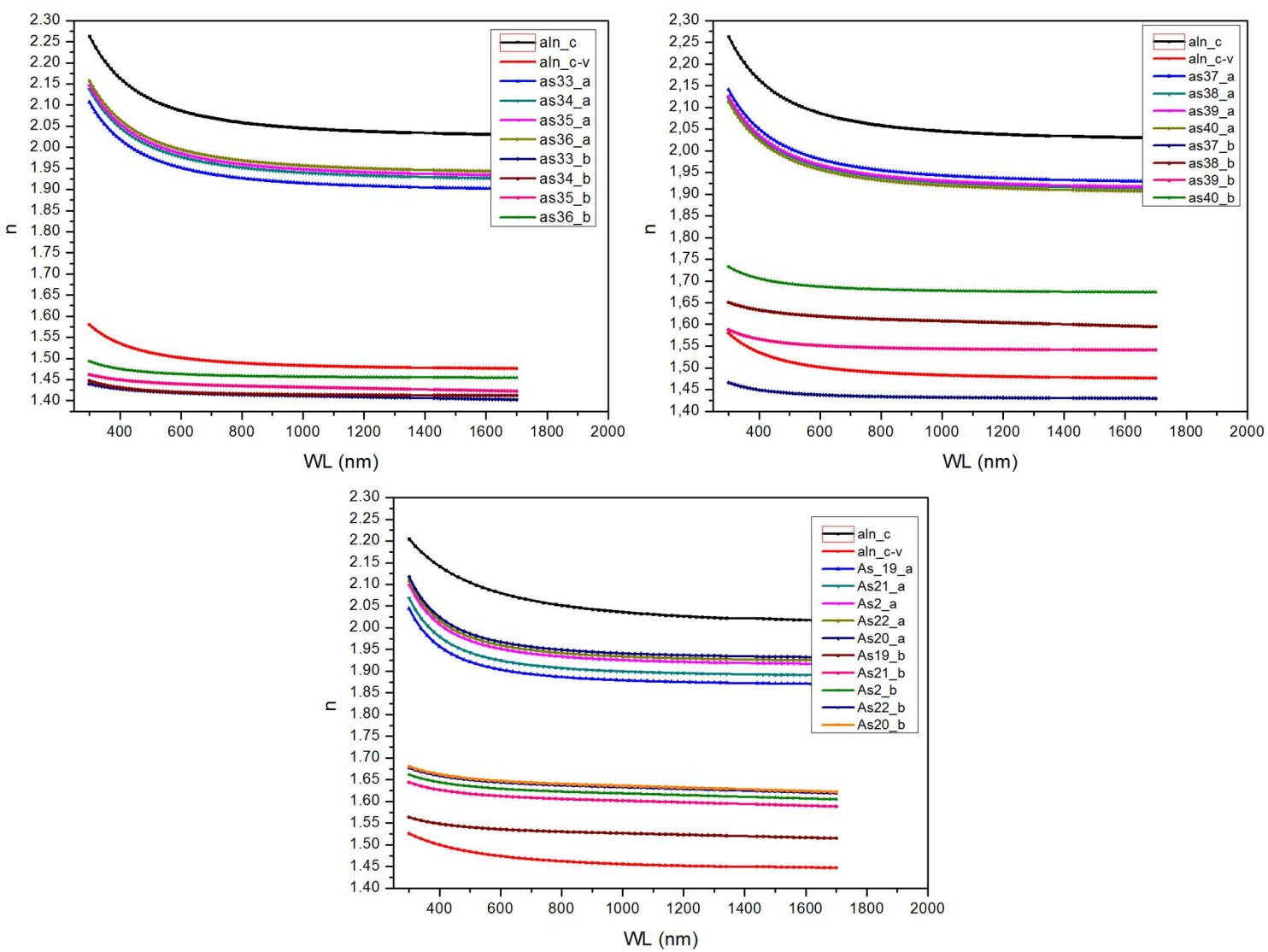

Fig. 6. Relationship between wavelength and refractive indices for all series of oxidation: (a) dry, (b) wet, (c) mixed.

above, contain the data following from modeling. "AlN Cauchy" layer is a layer of raw AlN after epitaxy, its thickness tends to zero with the oxidation time. "AlN Cauchy + Void" is called by us "infected by oxygen" AlN layer whose thickness is rising during oxidation. The third type of layer is an oxide layer " $\mathrm{Al}_{2} \mathrm{O}_{3}+$ Void". The employed AlN/Si structures were rather thin: there were used high temperature HT epilayers with thicknesses about $220 \mathrm{~nm}$ (dry and wet oxidation) and $\sim 270 \mathrm{~nm}$ (mixed oxidation). They were not monocrystalline. Diffusion of oxidation agent (oxygen or/and water steam) took place through the micro cavities on the surface of AlN. 
The refractive indices of all oxide composite layers for different thermal oxidation times (the data in the Table 1, Table 2, and Table 3) versus wavelength are collected in Fig. 6. In those diagrams, the curves for $\mathrm{Al}_{2} \mathrm{O}_{3}$ and composite layer AlN + Void are shown. In the samples names the following extensions were used: “_a” and "_b" relating "AlN Cauchy + Void" and " $\mathrm{Al}_{2} \mathrm{O}_{3}+$ Void" layers, respectively.

\section{EDS measurements}

Fig. 7 presents a typical diagram of the EDS counts. Silicon signal comes from substrate and carbon signal comes from MOVPE technology. Fig. 8 shows the atomic contents of nitrogen and oxygen in oxidized layers as a function of time of mixed oxidation. All the curves (for oxygen and nitrogen contents) can be fitted quite well by a sigmoidal function with Boltzmann model (not shown in Fig. 8).

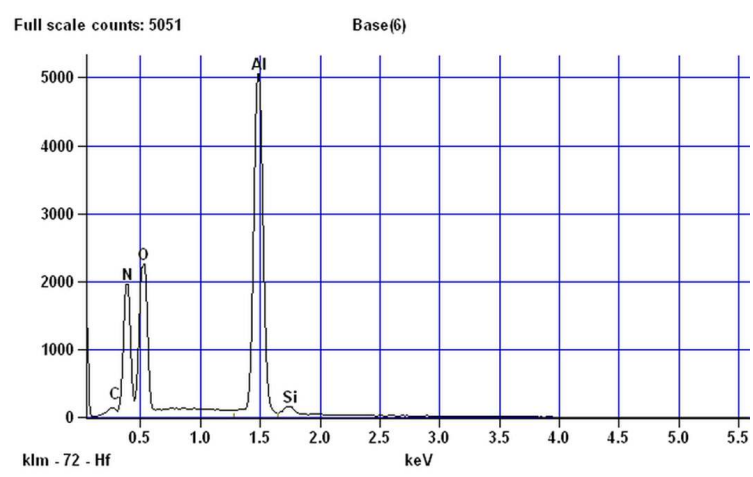

Fig. 7. EDS counts for sample As19 (oxidation time: $10 \mathrm{~min}, 5 \mathrm{kV}$ ).

One can observe that after 50 minute mixed oxidation, the contents of oxygen reaches the final value in $\mathrm{Al}_{2} \mathrm{O}_{3}$ of about $60 \%$. In addition, there is practically a lack of nitrogen.

\section{Conclusions}

Wet thermal oxidation of $\mathrm{AlN} / \mathrm{Si}(111)$ at a temperature above $1000{ }^{\circ} \mathrm{C}$ in the presence of various gas atmospheres was studied. The experiments were carried out in dry $\left(\mathrm{N}_{2}+\mathrm{O}_{2}\right)$, wet $\left(\mathrm{N}_{2}+\right.$ water steam) and mixed $\left(\mathrm{N}_{2}+\mathrm{O}_{2}+\right.$ water steam)

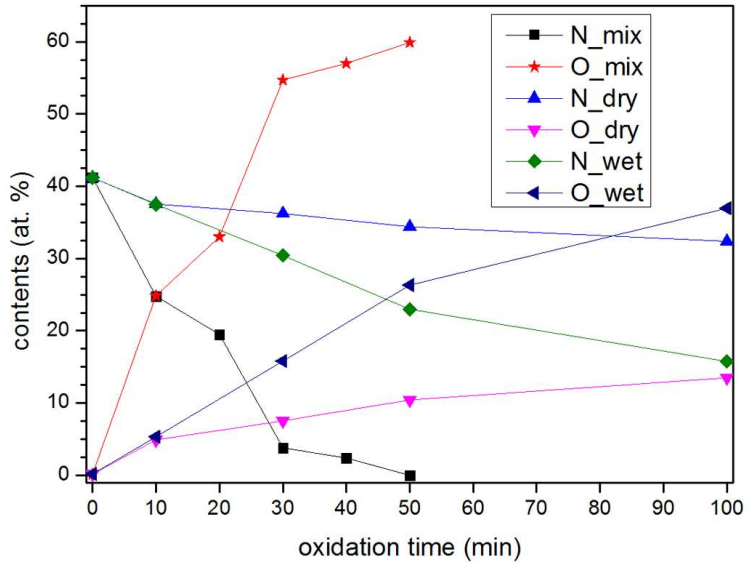

Fig. 8. Diagram of oxidation time vs. atomic contents of nitrogen and oxygen.

atmospheres. The time of the process was a variable. Simple modeling and fitting SE data gave us unsatisfactory results. We had to carry out advanced simulations to get a good match with the measured data. We have found that our oxides are not aluminum oxide $\mathrm{Al}_{2} \mathrm{O}_{3}$ but rather aluminum oxynitride with the content of oxygen in the crystal structure dependent on the time of the oxidation process and on the type of the oxidation (dry, wet, mixed). The obtained structures were complex and consisted of three layers: AlN, AlN "infected" by oxidation agent $\left(\mathrm{O}_{2}\right.$ or/and $\left.\mathrm{H}_{2} \mathrm{O}\right)$ and oxide layer $\mathrm{Al}_{2} \mathrm{O}_{3}$. Our observations show that mixed oxidation in the most effective method for production the oxidized AlN layers.

The data obtained by us indicate the need for detailed analysis of the AlN oxidation process, especially the influence of the atomic hydrogen, which will be made in the next paper.

\section{Acknowledgements}

Thanks for dr. Mateusz Wośko for epilayers preparation and dr. Andrzej Stafiniak for SEM observations. This research was partially supported by the Wroclaw University of Technology Statutory Grant, by the European Regional Development Fund, through the Grant Innovative Economy (POIG.01.01.02-00-008/08-05).

\section{References}

[1] Pearton S.J., Zolper J.C., Shul R.J., Ren F., J. Appl. Phys., 86 (1999), 1. 
[2] Kim H., Park S.-J., Hwang H., J. Vac. Sci. Technol. $B, 19$ (2001), 579.

[3] Nakano Y., Jimbo T., Appl. Phys. Lett., 82 (2003), 218.

[4] Wu J.Y., Wang H.H., Wang Y.H., Houng M.P., IEEE Electron. Device. Lett., 20 (1999), 18.

[5] MiczeK M., Mizue C., Hashizume T., AdamowICZ B., J. Appl. Phys., 103 (2008), 104510.

[6] Bidzinski P., Miczek M., Adamowicz B., Mizue CH., Hashizume T., Jpn. J. Appl. Phys., 50 (2011), 04DF08.

[7] Korbutowicz R., Prażmowska J., Wet thermal oxidation of GaAs and GaN. In: GrYM J. (Ed.), Semiconductor technologies, In-The, Vukovar, 2010, p. 105.
[8] Korbutowicz R., PRAŻMOWSKA J., WAGrowski Z., SzyszKa A., TŁaczaŁA M., Procedings of ASDAM 2008, Smolenice, Slovakia, 2008, 163.

[9] Bruggeman D.A.G., Ann. Phys.-Leipzig, 24 (5) (1935), 636.

[10] Zollner S., Konkar A., Gregory R.B., Wilson S.R., NiKISHIN S.A., TEMKIN H., MRS Spring Meeting San Francisco, 1999, Paper Y5.21.

Received 2015-08-16

Accepted 2015-11-16 